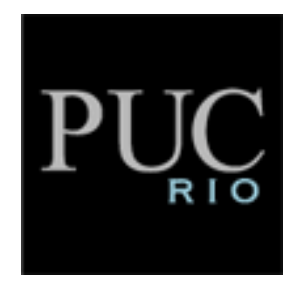

Pontificia Universidade CATtolica $_{\text {Do }}$

Barbara da Silva Lucas

Bolsa Família e as suas condicionalidades: análise das motivações para evasão e infrequência escolar na vida dos adolescentes

Artigo Científico como modalidade para o Trabalho de Conclusão do Curso de Especialização em Assistência Social e Direitos Humanos - PUC Rio, como requisito parcial para o título de Especialista em Assistência Social e Direitos Humanos.

Orientadora Prof ${ }^{a}$. Dr ${ }^{\mathrm{a}}$ Valéria Pereira Bastos 


\title{
Bolsa Família e as suas condicionalidades: análise das motivações para evasão e infrequência escolar na vida dos adolescentes $^{1}$
}

\author{
Barbara da Silva Lucas ${ }^{2}$
}

\section{Resumo}

O presente trabalho tem por finalidade a análise das principais motivações para a evasão e/ou infrequência escolar de alunos do projeto Aluno Presente no bairro de Magalhães Bastos entre janeiro de 2014 a julho de 2016, pois como a não permanência na escola reflete diretamente na condicionalidade do Programa Bolsa Família e a desistência pela escolarização se configura como principal motivação para a desvinculação do jovem da garantia do benefício, nos sentimos instigadas a conhecer melhor a questão, a fim de entender quais são os reais entraves do processo e verificar se existem algumas alternativas para reversão do quadro. Para complementar à análise, buscamos ouvir uma diretora da rede municipal de educação, no sentido de verificar quais são as suas impressões sobre o espaço escolar e seus sujeitos na busca de compreender se a escola cria obstáculos ou facilidades para manter seus alunos, e quais as estratégias efetivadas com as famílias que vivenciam a questão diante dessa condicionalidade, pois o que é direito acaba por vezes por se constituir como um fator cerceador na garantia de direitos aos beneficiários da política de assistência social.

\section{Palavras-Chave}

Projeto Aluno Presente; Educação; Evasão/infrequência; Programa Bolsa Família.

\footnotetext{
${ }^{1}$ Este artigo científico foi realizado a partir do trabalho enquanto articuladora local do Projeto Aluno Presente. A modalidade artigo científico é parte fundamental para a conclusão de curso da pós graduação Lato Sensu em Assistência Social e Direitos Humanos da PUC-Rio e sua construção foi orientada pela Professora Doutora Valéria Pereira Bastos, professora do departamento de Serviço Social da PUC-Rio cuja área de pesquisa é voltada para o estudo das Questões Socioambientais, Urbanas e Formas de Resistência Social.

${ }^{2}$ Assistente Social e aluna de Pós Graduação em Assistência Social e Direitos Humanos da PUCRio.
} 


\title{
Bolsa Família and its conditionalities: analysis of the motivations for school dropout and infrequency in adolescents' lives
}

\begin{abstract}
The present work has the purpose of analyzing the main motivations for school dropout and / or infrequency of students from the Present Student project in the Magalhães Bastos neighborhood between January 2014 and July 2016, since as non-permanence in school reflects directly on the Conditionality of the Bolsa Família Program, and the withdrawal from schooling is the main motivation for the phenomenon to untying the young person from the guarantee of the benefit, we feel encouraged to know the issue better, in order to understand what the real obstacles are in the process and to verify if there are some alternatives for reversing the frame. To complement the analysis, we sought to hear a director of the municipal education network, in order to verify what are their impressions about the school space and its subjects in the search to understand if the school creates obstacles or facilities to keep its students, and which ones strategies implemented with the families that experience the issue in the face of this conditionality, since what is law, sometimes becomes a restricting factor in guaranteeing rights to beneficiaries of social assistance policy.
\end{abstract}

\section{Keywords}

Aluno Presente Project; Education; School Dropout/Infrequency; Bolsa Família Program.

\section{Introdução}

O presente trabalho pretende abordar a problemática da evasão escolar e infrequência de adolescentes tendo como referência de estudo o bairro de Magalhães Bastos, zona oeste da cidade do Rio e a relação com a permanência no Programa Bolsa Família, a partir do trabalho no Projeto Aluno Presente, tendo vista a condicionalidade da matrícula e frequência regular à escola para acesso e permanência como beneficiário.

Os estudiosos da área de educação tiveram sua atenção voltada para o alarmante fato oficializado através dos dados do Censo / IBGE de 2010 de que cerca de 24.000 entre crianças e adolescentes de 6 a 14 anos se encontravam fora da escola ou em risco de evasão escolar somente na cidade do Rio de Janeiro.

A grave situação dentre outras mobilizações, impulsionou alguns pesquisadores e Organizações Não Governamentais na perspectiva de 
implantarem projetos que visassem minorar esse quadro. Neste sentido, após concorrer ao financiamento do projeto pela Fundação Education Above All, organização do Qatar que trabalha com projetos de educação e que possui um programa chamado Educate a Child e ter conseguido o financiamento, em parceria com a Secretaria Municipal de Educação do Rio, a Cidade Escola Aprendiz, ONG com experiência na área de educação, construiu o projeto "Aluno Presente" e iniciou dando seus primeiros passos na direção da reinserção de crianças e adolescentes de 6 a 14 anos na escola e na sua permanência nas unidades escolares.

Diante dos dados oficiais, foi elaborado pelo Observatório de Favelas ${ }^{3}$, um diagnóstico da cidade do Rio que indicou que a região mais afetada pela evasão e/ou infrequência escolar das crianças e adolescentes estava localizada na Zona Oeste da cidade, mais especificamente na área da $8^{\underline{a}}$ Coordenadoria Regional de Educação que abrangia os seguintes bairros: Guadalupe, Padre Miguel, Santíssimo, Magalhães Bastos, Bangu, Deodoro, Jardim Sulacap, Realengo, Campo dos Afonsos, Senador Camará e Vila Militar.

A primeira equipe de profissionais denominados articuladores locais foi composta por assistentes sociais, psicólogos, pedagogos entre outros e em dezembro de 2013 iniciou sua atuação na região com maior índice de evasões indicada pelo diagnóstico e somente meses depois foi se expandindo para todas as onze coordenadorias existentes na cidade onde até setembro de 2014 toda a cidade do Rio de Janeiro contava com a atuação do projeto.

O trabalho foi efetivado e foram realizados contatos direto com as famílias indicadas pela busca ativa e também com apoio de listas oficiais fornecidas pela Secretaria Municipal de Educação, que vinham vivendo a situação dos filhos encontrarem-se em situação de evadidos ou com efetiva infrequência escolar, portanto, a ideia era promover a inclusão dessas crianças nas unidades escolares, viabilizando condições através de parcerias com as demais instituições da sociedade civil e setores públicos para que elas não evadissem e se sentissem motivadas a permanecerem na escola.

O bairro do nosso estudo, conforme já informado será Magalhães Bastos, primeiro por pertencer ao grupo de bairros indicados pelo diagnóstico realizado e segundo por ser um bairro populoso, estimativa de 24430 habitantes, carentes de infraestrutura local, embora contem com algumas escolas de ensino

3 "O Observatório de Favelas é uma organização da sociedade civil de pesquisa, consultoria e ação pública dedicada à produção do conhecimento e de proposições políticas sobre as favelas e fenômenos urbanos". Para maiores informações: www.observatoriodefavelas.org.br 
fundamental e ensino médio, unidade de saúde básica e atualmente pela via expressa Transolímpica, que liga os bairros de Deodoro a Recreio dos Bandeirantes, mas no escopo da assistência social não há no bairro uma unidade de atenção básica da política, isto é, os Centros de Referência da Assistência Social - (CRAS), pois a que atende o território está localizada no bairro de Realengo. Por sinal, a cobertura abrange uma extensão territorial muito grande, que vai de Realengo a Deodoro, o que dificulta o alcance da política com maior qualidade pela população, levando-se em conta também o pouco quantitativo de profissionais do CRAS, cujo trabalho se torna muito difícil também para os técnicos, sendo necessário talvez, mais um equipamento físico para operacionalização da política de assistência social que pudesse redimensionar de forma mais equilibrada o atendimento à população usuária dos serviços.

A partir da experiência vivenciada no projeto, de início, pudemos identificar dois fatores que nos indicaram as demandas efetivas no processo de evasão e/ou infrequência escolar, a saber: primeiro a grande incidência na faixa etária entre 12 anos a 14 anos completos e a principal motivação para a evasão/infrequência apontou para 0 desinteresse pelo processo de escolarização, ocasionado dentre outras questões, mas principalmente pelo não interesse dos adolescentes pela escola, já que os projetos pedagógicos atuais não absorvem elementos que sejam atrativos aos jovens, somente a transmissão do conhecimento científico não forma um sujeito crítico, capaz de entender e questionar o status quo. Com isto, ambos os dados se relacionam diretamente.

A atuação do projeto no bairro permitiu um acúmulo de informações, coletadas através das entrevistas realizadas no período de janeiro de 2014 a julho de 2016 que favoreceram algumas análises sobre as famílias atendidas na região, pontos que abordaremos a seguir.

Em complementação à análise obtida com a atuação do projeto, foi utilizado como instrumental para construção deste trabalho, a escuta à uma diretora de escola de ensino fundamental do bairro, buscando trazer a visão da educadora sobre as apreensões do universo escolar, sobre os sujeitos envolvidos no processo, tentando entender a partir disto se a escola pode ser um obstáculo a permanência do aluno na escola.

A partir das questões que envolvem a evasão/infrequência, soma-se a isto o desejo de tentar refletir sobre as dificuldades que famílias que vivenciam tal situação enfrentam para a permanência no programa diante das 
condicionalidades exigidas, somadas à falha de interlocução das políticas setoriais.

1

\section{Magalhães Bastos sob a ótica do projeto: motivações para o abandono e/ou infrequência escolar}

Para entender a realidade socioeconomica das famílias e a dinâmica que as envolve, o trabalho inicialmente realizado nos permitiu fazer um levantamento das demandas familiares, onde pudemos compreender quais os motivos para as crianças/adolescentes estarem fora da escola/infrequentes, qual a renda familiar, se são ou já foram beneficiários de algum programa de transferência de renda, grau de escolaridade do responsável, dentre outros. Esta abordagem nos auxiliou no sentido de compreender a realidade das famílias e traçar um perfil socioeconômico, objetivando buscar estratégias para auxiliá-las na construção de alternativas que permitam a superação de possíveis questões que possam cercear seus direitos.

A partir do perfil analisado no bairro, conclui-se que em mais da metade das famílias: os responsáveis trabalham, possuem ensino fundamental incompleto e possuem renda entre meio e dois salários mínimos. Desta forma, se evidencia que se configuram por famílias de trabalhadores de baixa renda e pouco acesso à escolarização, o que pode ecoar diretamente na manutenção do aluno na escola. Este reflexo pode ser decorrente de vulnerabilidade social vivenciada pela família ou pelo fato dos responsáveis precisarem sair para trabalhar e não conseguirem ter o controle sobre a frequência escolar ou talvez ainda pela pouca escolarização, os responsáveis não compreenderem a importância do ensino. Baseado em Paiva (1992), BACKX (2006) diz que:

\footnotetext{
A criança oriunda da classe trabalhadora dificilmente encontra em seu convívio condições de perceber oportunidades futuras a partir da escola: sua família, quando tem essa informação, nem sempre consegue transmiti-la de modo convincente, seja por suas dúvidas ou por dificuldades discursivas decorrentes de uma baixa escolaridade. (BACKX, 2006, p: 130-131)
}

Outro ponto que nos foi permitido identificar e entender consiste no fato de - maior índice de infrequentes ou que evadiram das unidades escolares pertencem à faixa etária de 12 anos a 14 anos completos, portanto, o foco maior 
está voltado para os adolescentes, sendo assim, este artigo tende a focar mais neste público alvo do que nas crianças.

Em primeiro lugar, o motivo principal pela evasão ou infrequência escolar apontado pelo estudo está relacionado ao desinteresse do aluno pela escolarização, tendo em vista que a forma como o ensino é ministrado não apresenta atratividade na fixação dos adolescentes ao ambiente escolar. Acreditamos que tal fato possa estar relacionado a inúmeras dimensões, tais como: escola sem estratégias pedagógicas que permitam o interesse dos jovens pelo processo escolar e que saibam lidar com as diferenças existentes entre as pessoas, não queiram apenas encaixá-las em determinados padrões sociais, professores despreparados e desmotivados pela desvalorização profissional, dentre elas os baixos salários, são aspectos que não cabem ser aprofundadas neste momento. Estes fatores podem refletir diretamente na não compreensão por parte dos adolescentes da importância da escolarização e do que ela de fato significa.

O desinteresse pela escolarização pode estar atrelado também ao papel que a escola significa na vida dos alunos hoje. Com processos pedagógicos que não atraem o alunado, principalmente adolescentes, em sua fase de descobertas e formatação de personalidade, a educação formal pública necessita trazer para dentro dos muros da escola, aspectos do cotidiano de seus discentes, fatores que envolvam a realidade das classes populares, habitualmente público-alvo deste segmento. Baseado em Paulo Freire, a escola deve ser caracterizada por uma troca de conhecimento dos sujeitos envolvidos, independente de sua classe social e sua posição na sociedade. Formar o aluno para ser um cidadão, crítico e que consiga fazer a leitura do mundo tal como ele é, e não apenas passar-Ihe o conhecimento acadêmico, se faz extremamente iminente para que a escola passe a cumprir sua função social. Concordando com Freire (2002):

Por isso mesmo pensar certo coloca ao professor ou, mais amplamente, à escola, o dever de não só respeitar os saberes com que os educandos, sobretudo os da classes populares, chegam a ela - saberes socialmente construídos na prática comunitária - mas também, como há mais de trinta anos venho sugerindo, discutir com os alunos a razão de ser de alguns desses saberes em relação com o ensino dos conteúdos. Por que não aproveitar a experiência que têm os alunos de viver em áreas da cidade descuidadas pelo poder público para discutir, por exemplo, a poluição dos riachos e dos córregos e os baixos níveis de bem-estar das populações, os lixões e os riscos que oferecem à saúde das gentes. Por que não há lixões no coração dos bairros ricos e mesmo puramente remediados dos centros urbanos? Esta pergunta é considerada em si demagógica e reveladora da má vontade de quem a faz. É pergunta de subversivo, dizem certos defensores da democracia. Por que não discutir com os alunos a realidade concreta a que se 
deva associar a disciplina cujo conteúdo se ensina, a realidade agressiva em que a violência é a constante e a convivência das pessoas é muito maior com a morte do que com a vida? Por que não estabelecer uma necessária "intimidade" entre os saberes curriculares fundamentais aos alunos e a experiência social que eles têm como indivíduos? Por que não discutir as implicações políticas e ideológicas de um tal descaso dos dominantes pelas áreas pobres da cidade? A ética de classe embutida neste descaso? Porque, dirá um educador reacionariamente pragmático, a escola não tem nada que ver com isso. A escola não é partido. Ela tem que ensinar os conteúdos, transferi-los aos alunos. Aprendidos, estes operam por si mesmos. (FREIRE, 2002, p:15)

Além de não permitir o acesso a elementos alternativos de atração para o alunado, um sistema escolar que exige um padrão específico de aluno, não compreendendo suas diferenças ideológicas e culturais, acarreta também no desinteresse pela escolarização, já que o mesmo não se sente pertencente àquele mundo e não mais vê sentido em persistir trilhando um caminho que não o aceita, não o reconhece em meio às suas diferenças. Desta forma, o processo de escolarização não se faz primordial na vida dos adolescentes, já que não conseguem enxergar a importância deste processo em seu presente e futuro.

Outro fator que pode acarretar em alunos desestimularem do prosseguimento ao ensino está relacionado à defasagem escolar, o que também pode estar atrelado a fatores relacionados à dificuldade de aprendizagem e reprovação escolar. Com métodos didáticos de aplicação em massa do conhecimento técnico sem que o ensino seja ministrado com técnicas pedagógicas atraentes, que desperte o interesse do jovem, isto acaba por refletir na reprovação escolar e no chamado fracasso escolar ${ }^{4}$. Quando vivenciam a situação de reprovação escolar por anos seguidos, estes alunos se encontram em situação de distorção idade-série e com isto, não sentem desejo pela permanência em turmas com crianças menores que cursam grupamentos regulares.

De acordo com o sistema educacional vigente na Secretaria de Educação do Município do Rio, as regras para matrícula de alunos no período regular se inicia quase ao fim de cada ano letivo através da pré-matrícula digital, onde alunos que estejam em situação de distorção idade-série ${ }^{5}$, precisam realizar uma avaliação onde serão medidos seus conhecimentos e possam ser encaminhados a cursar turmas de projeto de correção de fluxo escolar ${ }^{6}$. Os alunos que são

\footnotetext{
4 Sobre fracasso escolar ver em BACKX (2006).

5 Alunos em distorção idade-série se caracterizam por aquelas crianças/adolescentes cuja série a ser cursada não corresponde mais à idade que possui (segundo as orientações do MEC), devido seguidos anos de reprovação escolar ou ocasionado pelo demasiado tempo em que ficou fora da escola.

6 Correção de fluxo escolar consiste em projetos realizados pelas Secretarias de Educação com apoio do MEC com o objetivo de corrigir a defasagem escolar através da criação de turmas
} 
matriculados ao longo do ano letivo já não possuem mais esta possibilidade e então são inseridos em turmas regulares, independente de sua idade (somente os que possuem 16 anos ou mais devem ser incluídos em turmas do Programa de Educação de Jovens e Adultos - PEJA).

Mesmo com o entendimento que os projetos de correção de fluxo precisam ter uma sequência ao longo do ano e por isto não podem acolher novos alunos que estejam fora da escola fora do período habitual de matrículas por questões pedagógicas, a questão da inserção do aluno em defasagem em turmas regulares pode causar constrangimentos ao aluno. $O$ adolescente se vê partilhando do ambiente escolar com crianças com idades inferiores, o que fatalmente pode levar ao desinteresse pela escolarização e consequentemente ao abandono escolar.

O segundo ponto referente às motivações pela evasão/infrequência escolar ocorre sobre as demandas de saúde ou necessidades educacionais especiais. As questões de demanda de saúde de alunos infrequentes envolviam regularmente o fato de alunos faltarem por motivos de doença e os responsáveis não comunicarem a situação à escola ou comunicarem e, mediante a falta do atestado médico (muitas famílias tratavam em casa das doenças dos filhos por já saberem do tratamento a ser realizado ou por levarem em unidades de saúde pública que não concedem atestado médico), as ausências não poderem ser justificadas.

As mudanças de domicílio, viagens ou deslocamentos frequentes também aparecem como motivação para o adolescente estar fora da escola/infrequente. Ocorre que durante a identificação da criança ela se encontra nesta situação, pois chegou de outro bairro ou município e sua família ainda não conseguiu vaga escolar em seu novo local de moradia. O mesmo, claro, ocorre inversamente. Há mudanças do bairro de Magalhães Bastos para outras localidades e a criança/adolescente da mesma forma, dependendo do tempo, perde a vaga na unidade escolar, necessitando assim percorrer todo um novo caminho para garantir uma vaga em unidade de ensino.

Aspectos relacionados a questões familiares ou de vulnerabilidade social também se mostram como fator que incide sobre a evasão/infrequência escolar. As expressões da questão social que se fazem presentes mostram que a política de educação pode estar sendo uma das expressões da falha/falta de acesso e

formadas somente por alunos nesta condição e também, normalmente, onde haja uma aceleração do conteúdo escolar durante o ano letivo a fim de que a escolaridade seja ajustada e retorne a seu fluxo adequado. 
interlocução de diversas políticas setoriais. A assistência social pode e deve se fazer presente na realidade social não principalmente através dos programas de transferência de renda, estes, se fazem de extrema necessidade, mas deveriam ser complementares à uma política de redistribuição de renda, em luta por uma sociedade menos desigual, aliada ao acesso de diversos serviços e oportunidades que possibilitassem de fato a proteção social.

Os fatores citados comprovam a urgente necessidade da comunicação e ação entre as políticas sociais para que haja uma rede de proteção social articulada que possa permitir de fato que os direitos sociais sejam efetivamente garantidos.

\section{2 \\ O fator desistência pela escolarização: A experiência de uma diretora de ensino fundamental de Magalhães Bastos}

Durante a construção das reflexões sobre 0 processo de evasão/infrequência escolar, foi possível ouvir uma profissional da área de educação do município, que exerce a função de diretora de escola de ensino fundamental no bairro de Magalhães Bastos como mais uma alternativa na busca de compreender as apreensões de uma técnica da ponta da política de educação e, a partir de sua fala tentar compreender com as questões que envolvem suas percepções sobre o papel da escola, as motivações para infrequência/evasão escolar, e ainda o papel dos sujeitos envolvidos neste processo, dentre outros aspectos.

Sendo assim, ao discorrer sobre o papel da escola na formação da pessoa, a educadora $X$ relata que:

\footnotetext{
"Sem prescindir da importância da família na formação da pessoa, considero a escola fundamental por ser um espaço de convivência onde circulam saberes, valores e vivências de enorme diversidade. Um trabalho bem executado, e isso envolve a atuação conjunta dos diversos segmentos que compõem o universo escolar, é capaz de desenvolver no educando capacidades que Ihes permitirão interagir com toda essa diversidade, adequando-a aos seus valores e até mesmo excluindo experiências que pouco acrescentarão à sua vida pessoal" (Educadora $X, 2017)$.
}

Considera-se nesta análise que a escola como um espaço de formação integrada entre seus sujeitos se faz necessária para a construção de uma nova concepção de escola, formando cidadãos, críticos e que é passo fundamental inclusive para a idealização de uma nova ordem social. Para isto, além dos 
sujeitos envolvidos no âmbito escolar, se faz necessário, como relata a educadora, considerar a família como um dos elementos centrais na formação da pessoa humana e este elemento é primordial na constituição da pessoa. Questão esta ratificada na legislação, tanto na Constituição Federal de 1988 quanto no Estatuto da Criança e do Adolescente, de 1990, onde mostra que a família, bem como comunidade, sociedade e poder público também devem proporcionar à criança/adolescente condições de acesso aos "direitos referentes à vida, à saúde, à alimentação, à educação, ao esporte, ao lazer, à profissionalização, à cultura, à dignidade, ao respeito, à liberdade e à convivência familiar e comunitária." (Constituição Federal, 1988). Estes elementos se configuram como a base para a permanência de adolescentes no espaço escolar.

A partir deste olhar, se faz necessário buscar ouvir também quais são as impressões que os alunos, que os professores e que a comunidade ao redor possuem sobre a escola. De acordo com a visão da educadora, como a escola funciona em tempo integral, analisa que a comunidade visualiza a unidade como espaço onde os adolescentes podem ficar em segurança pelo período de sete horas. Desta forma, compreende-se que não considera que a população tenha a escola como espaço fundamental de formação de cidadãos, e sim apenas como estrutura que abriga jovens em boa parte do tempo.

Para a profissional ouvida, os alunos entendem a escola como espaço onde recebem o conhecimento através de conteúdos que não lhes é atrativo, portanto, compete com a realidade em que vivem, o que com isso, os leva ao desinteresse pela escola. Esta realidade confirma com as conclusões chegadas no tópico acima, de que a escola desvinculada de elementos pedagógicos que estimulem a atenção do jovem, que se faça palco de interação entre os saberes, não apenas recepção e absorção de conteúdo de forma mecanizada se faz de extrema importância para a garantia de que este jovem tenha interesse em prosseguir de forma prazerosa com o processo de escolarização.

Da mesma forma, ao analisar as percepções de docentes sobre a escola, considera que muitos ainda o fazem pela realização profissional, usando de técnicas diferenciadas do padrão utilizado, interagindo com os jovens, estabelecendo vínculos com eles, porém alguns fazem do trabalho apenas a obrigação para seu sustento.

No tocante às relações entre docentes e discentes, é avaliado pela diretora que: 
"Observo que, de um modo geral, a relação é conflituosa. Na minha opinião, dois motivos são primordiais para justificar o conflito: o "fosso social" existente entre professor e aluno; e o desalinhamento entre o discurso e a prática. É claro que existem exceções para cada uma dessas situações. O fato é que docentes de classe mais abastada tomam como referência suas experiências de vida, calcadas em famílias bem estruturadas, com mãe e pai presentes, o que não encontra correspondência com a vida dos jovens estudantes. Quanto ao desalinhamento discurso/prática, observo que os valores abordados nos discursos são pouco ou nada materializados no dia a dia através das atitudes. A pedagogia da presença (Ensinar através das atitudes) é quase inexistente. Como posso penalizar o aluno que chega atrasado se eu mesmo ajo assim? Essa deveria ser uma reflexão permanente no ambiente escolar" (Educadora X, 2017).

Desta forma, analisa-se como fator que pode acarretar no desestímulo à escolarização o fato de professores de classe média, que possuem experiências diferentes das vivenciadas por alunos de classes populares, possuírem uma visão mais estereotipada, não compreenderem o modo de vida desses jovens, o que se verifica até mesmo através da não interação com sua realidade, quando não tentam trazer parte do cotidiano desses jovens como ferramenta pedagógica a ser trabalhada dentro dos muros da escola. O trabalho doutrinador, de fazer os jovens se encaixarem em padrões pré-determinados socialmente indica também sua visão de mundo. As diferenças advindas das relações entre classes são expressas pelo discurso comparativo entre suas vidas e a de jovens, oriundos de classes populares e que possuem em sua trajetória de vida elementos desestimuladores e falha no acesso de oportunidades. Sobre as percepções do homem no mundo, FREIRE (2007) diz que:

Se, de fato, não é possível entendê-los fora de suas relações dialéticas com o mundo, se estas existem independentemente de se eles as percebem ou não, e independentemente de como as percebem, é verdade também que a sua forma de atuar, sendo esta ou aquela, é função, em grande parte, de como se percebam o mundo". (FREIRE, 2007, p: 82-83)

Como pontos principais que podem comprometer o interesse do aluno pela escolarização, são citados os seguintes fatores: "práticas pedagógicas pouco inovadoras; excesso de atividades acadêmicas; ausência de momentos de descontração e atividades extraclasse, como passeios". Concordando com tal afirmativa sobre tal processo, verifica-se que se faz urgente uma revisão dos processos pedagógicos existentes, não tendo como objetivo principal somente a transmissão dos conteúdos acadêmicos de forma a massificar a produção do conhecimento. Além disto, é imprescindível além de formação adequada ao professor, condições para que ele exerça a profissão de modo a garantir que a função social da educação seja cumprida. 
Com relação à exigência da frequência escolar como condicionalidade para permanência no Programa Bolsa Família, a educadora analisa que este fator não é mais positivo, pois as famílias agem com indiferença quanto à suspensão do benefício e não dão tanta importância à frequência escolar como condição para manutenção deste, o que acarreta na frequência abaixo do esperado e a procura de informações sobre frequência muitas vezes ocorre quando sofrem alguma sanção do benefício.

A situação ilustra o possível não entendimento dos responsáveis sobre a importância do processo de escolarização de seus filhos ou até mesmo a desistência pela manutenção dos jovens à escola após longo histórico de infrequência, não saberem mais lidar com as situações que envolvem o universo juvenil e com isto muitos acabam por abrir mão da continuidade da escolarização de seus filhos. Desta forma, a situação corre em momento circular, já que muitos dos pais também abandonaram a escola no ensino fundamental, como visto através de pesquisa, por diversas motivações mas também a repetição da histórias acabam por se fazer presente.

3

\section{A permanência das famílias no Programa Bolsa Família versus a infrequência e/ou evasão escolar}

No seio da luta de classes, as políticas sociais surgem tanto como resposta do Estado para amenizar as reivindicações da classe trabalhadora, que passam a insurgir por melhores condições de vida e de reprodução social no século XIX quanto como forma de legitimação do Estado, que propõe as políticas também como forma de obter o apoio da classe trabalhadora.

O Programa Bolsa Família surge em 2004 como forma de unificação de todos os benefícios socioassistenciais concedidos na esfera municipal, estadual e federal. Sabendo que as políticas sociais se configuram como paliativas em relação ao trato da desigualdade social e da Questão Social promovida pelo sistema de produção capitalista, concordando com Yazbek (2003):

Os contrastes entre miséria e abundância observáveis "a olho nu" em nossa experiência diária nos mostram que a evolução econômica do capitalismo brasileiro fortaleceu mais a desigualdade do que a diminuiu. Sabemos que o Estado, para obter legitimidade, necessita desenvolver ações que pelo menos no nível da aparência se voltem para o enfrentamento dessa desigualdade. (YAZBEK, 2003, p:40) 
Desde a criação do Programa Bolsa Família sob a lei 10.836/2004, o programa social de transferência de renda condicionado vincula além de condicionalidades na saúde, também a exigência da matrícula e frequência regular à escola como um dos critérios fundamentais para acesso ao benefício.

Durante o período da pesquisa que origina o processo metodológico deste estudo, foi identificado pelo projeto que quase metade de crianças e adolescentes domiciliados no bairro e cadastrados no projeto (de 6 a 14 anos) são vinculados a algum programa social, eles e suas famílias. Deste quantitativo, a grande maioria se vincula ao Programa Bolsa Família. Como condição para direito ao programa, as famílias devem manter a frequência de minimamente $85 \%$ para crianças e adolescentes na faixa etária de 6 a 15 anos e $75 \%$ para jovens de 16 a 17 anos.

Por mais que existam legislações do extinto Ministério do Desenvolvimento Social e Combate à Fome - MDS que norteiem a operacionalização das condicionalidades e suas respectivas ações através da intersetorialidade, habitualmente essas diretrizes não ocorrem de maneira tão satisfatória e eficaz no trato das questões sociais. Como afirma a Portaria 321/2008 do MDS em seu capítulo I, inciso III, faz-se necessária esta interlocução:

III - sistematização de informações sobre famílias beneficiárias do Programa Bolsa Família - PBF em situação de descumprimento de condicionalidades para subsidiar o acompanhamento por outras políticas públicas, de forma a reduzir as vulnerabilidades de tais famílias. (BRASIL, Portaria 321/2008).

O processo de acompanhamento de frequência escolar de uma criança/adolescente vinculado ao programa ocorre de forma intersetorial, pois as escolas repassam a porcentagem da presença para o sistema do programa, através do projeto Presença, sendo desta forma, a frequência regulada através de mecanismos tecnológicos que podem ser inflexíveis no trato de diversas expressões da Questão Social que permeiam o cotidiano das classes populares.

Fruto da burocratização da gestão das políticas sociais, inflexibilidade e falta de articulação entre as políticas sociais, normalmente a única forma de que as faltas sejam abonadas nas escolas se faz mediante a apresentação de atestado médico em casos de doença, de forma geral, muitas vezes são desconsideradas situações em que haja alguma problemática familiar ou de vulnerabilidade social, estes fatores além de não humanizados, acabam por dificultar a situação de famílias diante do acesso ao programa de transferência de renda. 
Desta forma a articulação intersetorial que se faz necessária para o funcionamento das políticas sociais e proporcionar o acesso aos direitos sociais, se torna falha e precisa ser reconsiderada. Cada instituição realizando apenas seu papel burocrático no atendimento das demandas, sem considerar a totalidade das necessidades humanas, os objetivos das políticas se esvaem. Concordando com Mioto \& Schutz (2011):

Para garanti-los, as necessidades sociais devem ser contempladas por estas políticas de forma integral, ou seja, em sua totalidade. Por esta razão, o atendimento dessas necessidades por estruturas institucionais e posturas profissionais estanques é ineficiente. Não é possível garantir o direito a saúde, por exemplo, sem que sejam contempladas necessidades relacionadas ao lazer, educação, saneamento básico, entre outras. No entanto, as políticas públicas e dos serviços públicos se configuram de forma setorizada. (MIOTO, SCHUTZ, 2011, p: 3)

As sanções sofridas por famílias que descumpram alguma das condições de acesso ao programa são advertência, bloqueio, suspensão (1), suspensão (2) e cancelamento, caso as faltas ocorram em cinco períodos consecutivos.

As reuniões ofertadas pelos CRAS para famílias em quebra de condicionalidade $^{7}$, podem por um lado ser representadas pela tentativa de prevenir possíveis sanções futuras e definitivas, como o cancelamento do benefício, porém estão mais propensas a ser parte de uma responsabilização e consequente punição apenas das famílias para o cumprimento de condicionalidades do programa. Levando-se em conta que as políticas setoriais precisariam trabalhar em comunicação e ação conjuntas para a superação de questões que possam contribuir para a permanência de fato de um aluno na unidade escolar. Baseado e concordando com o pensamento de Dal Bello (2016):

Inflexíveis às desigualdades territoriais, os indicativos de descumprimento de condicionalidades na educação reforçam perspectivas individuais, limitando a política de assistência social na identificação da pobreza em suas multideterminações e, logo, no reconhecimento de direitos, almejados no fortalecimento intersetorial, no diálogo com as políticas setoriais, como é a educação. (DAL BELLO, 2016, p: 240)

\footnotetext{
7 Reuniões com famílias de quebra de condicionalidades se configuram quando algum membro da família infringe alguma das condicionalidades (na saúde, educação). Durante as reuniões no CRAS de seu território com técnica da unidade de assistência social são expostos temas para conscientização, serem alertadas em casos da não ciência das faltas, retirada de dúvidas quanto à frequência regular à escola, etc.
} 
Além da necessidade de maior e melhor interlocução intersetorial, se faz necessário a revisão da divisão territorial dos aparelhos da Assistência Social. Os equipamentos atualmente precisam cobrir uma área territorial ou populacional muito extensa para poucos profissionais. Ocorre com isso uma demanda muito grande de acompanhamentos familiares aos quais os técnicos precisam atender, acompanhar, realizar relatórios e todas as demais questões que envolvem o trabalho profissional, e o que acaba por dificultar a plena garantia do direito social da Assistência Social.

Uma observação importante realizada ao longo do trabalho enquanto componente do corpo técnico do projeto Aluno Presente se faz presente na observação e reflexão sobre a quantidade de famílias que deixam de ter acesso ao programa, pois uma criança/adolescente na casa apresentou situações de falta e com isto a permanência da família como um todo ao programa é afetada, mesmo que as demais crianças/adolescentes do domicílio possuam a frequência exigida pelo programa, fazendo com que esta inflexibilidade seja um percalço no acesso aos direitos socioassistenciais.

Famílias que muitas vezes passam por situações de vulnerabilidade social, necessitam do auxílio financeiro e após perderem esta renda se torna muito difícil reavê-lo. Mesmo as políticas sociais representando aspecto procrastinador no modo de produção capitalista, como já abordado, programas como o Bolsa Família, - embora se façam necessárias outras questões além da transferência de renda para trato da desigualdade social e da má distribuição de renda que não cabem ser discutidas amplamente neste trabalho - são de extrema importância e representam um avanço na luta da classe trabalhadora. De acordo com Yazbek (2003):

\footnotetext{
Neste sentido, do ponto de vista conceitual, não podemos deslocar a questão do âmbito estrutural da sociedade capitalista, tendo presente que 0 assistencial não altera questões estruturais; pelo contrário, muitas vezes as oculta. Isso não significa que se deva negá-lo ou não reconhecer sua necessidade histórica, pois as políticas de assistência, como as demais políticas no âmbito da gestão estatal da reprodução da força de trabalho, buscam responder a interesses contraditórios, engendrados por diferentes instâncias da sociedade, e assim não se configuram como simples produtos dos interesses dos "de cima", mas como espaço onde também estão presentes os interesses dos subalternizados da sociedade. (YAZBEK, 2003, p: 53)
}

Desta forma, a gestão da condicionalidade não pode estar atrelada somente à informações digitais e rígidas, precisa da humanização do sistema no sentido de que os fatos sejam avaliados caso a caso, através de atendimento 
com assistentes sociais, que possam tentar entender as circunstâncias de cada situação e assim interpretar o cenário entendendo que a quebra dessas condicionalidades podem (e devem) estar atreladas às expressões da questão social.

\section{Considerações Finais:}

A principal motivação para a evasão e/ou infrequência escolar, ou seja, para a desistência de jovens pela escolarização formal requer também uma mudança estrutural no sistema educacional. Trazer para a escola atividades que estimulem o interesse do aluno pela escola, elementos que fazem parte de seu cotidiano e que possam favorecer sua permanência na escola, podem ser alternativas para a mudança do quadro atual. Com elementos inovadores, conteúdos diferenciados do que comumente é posto, tendem a ser impulsionadores para a constante frequência e participação dos jovens no processo de aprendizagem.

Professores bem preparados, que norteiem a escolarização na emancipação do jovem enquanto ser social se fazem de extrema necessidade para revisão da função da escola hoje. Docentes que respeitem e valorizem a diversidade cultural existente entre os sujeitos e saibam trabalhar sobre elas, não sobrepondo a produção em massa de informações sobre a troca que pode existir entre os saberes dos envolvidos no processo. Para isto se faz necessário também a valorização profissional não somente do professor e sim de todos os agentes envolvidos na política educacional, onde o jovem pode também se sentir acolhido.

A falha de comunicação/ação e a burocratização institucional ainda se fazem presentes entre as políticas sociais hoje, mesmo que as resoluções governamentais se esforcem para a superação dos entraves intersetoriais, o cotidiano ainda é marcado por estes obstáculos. A não compreensão de profissionais e instituições de que a política precisa de elementos otimizadores para funcionar com qualidade e não apenas a realização estrita da função de cada profissional, sem ultrapassar as barreiras burocratizantes que permeiam a sociedade, se faz necessária para o objetivo central da intersetorialidade, que é o trabalho articulado das políticas sociais para a superação de vulnerabilidades sociais.

Na política de educação, por exemplo, se faz necessária uma interlocução mais direta com a política de saúde e assistência social para acessar um 
entendimento da infrequência escolar com uma visão mais humanizada. Para que em casos de necessidade, os alunos e suas famílias possam ser encaminhados para as unidades de saúde pública sem elementos burocratizantes e que o contrário também possa ocorrer, em casos em que a saúde necessite de orientações, encaminhamentos da escola, que as relações possam ser mais próximas e eficazes. Quando um aluno falta aulas por motivos de saúde, tendo passado pela unidade, mesmo que a família não tenha acesso ao atestado médico/comparecimento, se faz urgente um mecanismo que possa permitir que a unidade passe a justificativa diretamente para o CRAS e escola, a fim de que todos os setores possam acompanhar a situação do aluno, entendendo-o em sua totalidade e não em ações fragmentadas, que não se relacionam e acabam por falir uma lógica de acesso ao direito, quando muitas vezes, metade deles são alcançados por entraves em outras políticas.

As mudanças de municípios, estados, podem também fragilizar o acesso ao direito à educação quando obstruem a matrícula de uma criança em outra localidade por falta por exemplo, de declaração de escolaridade. É sabido que a lei impõe que nenhuma documentação seja empecilho para a matrícula de uma criança, porém ainda ocorrem em unidades de ensino o obstáculo para a concretização do direito. Nestes casos, a intersetorialidade se faz necessária a fim de que haja uma integração entre as instâncias federativas em busca de acesso a documentações de forma simples, objetiva e sem impedimentos.

À política de Assistência Social se faz indispensável reconsiderar diversos aspectos. Uma delas se faz necessária através de uma maior flexibilidade com relação às diversas problemáticas que podem envolver a permanência no programa, criando alternativas para as famílias que tenham passado por alguma situação de evasão ou seguidas infrequências de algum dos filhos, não tenham o benefício familiar integralmente suspenso.

Compreendemos que se faz necessária a revisão de divisões territoriais de cada CRAS, tanto por questões territoriais amplas de cobertura quanto pela quantidade de famílias que cada aparelho tem por responsabilidade. $O$ acesso da população aos aparelhos pode ser prejudicado pela distância e também como não há suficiente quantidade de técnicos que operam na política, por vezes os mesmos não conseguem corresponder adequadamente às demandas que the são impostas, deixando a desejar a oferta qualitativa dos serviços. 


\section{Referências:}

BRASIL. Constituição (1988). Constituição [da] Republica Federativa do Brasil. Brasília, DF: Senado Federal. Disponível em: http://www.planalto.gov.br/ccivil 03/constituicao/constituicaocompilado.htm Acesso em: 24 de jan. 2017.

Adolescente.

Lei no 8069, de 13 de julho de 1990. Estatuto da Criança e do $<$ http://www.planalto.gov.br/ccivil 03/leis/L8069.htm> Acesso em: 24 de jan. 2017.

Lei no 9.394 de 20 de dezembro de 1996. Estabelece as diretrizes e bases da educação nacional. Brasília, 1996. Disponível em: <www.planalto.gov.br>. Acesso em: 08 jan. 2017.

Lei no $\mathbf{1 0 . 8 3 6}$ de $\mathbf{9}$ de janeiro de 2004. Cria o Programa Bolsa Família e dá outras providências. Brasília, 2004. Disponível em: <www.planalto.gov.br>. Acesso em: 07 jan. 2017.

Portaria 321, de 29 de setembro de 2008. Regulamenta a gestão das condicionalidades do Programa Bolsa Família. Diário Oficial da União; Poder Executivo, 2008. Disponível em: < http://www.direito.mppr.mp.br/arquivos/File/Portaria-MDS-n321-2008.pdf>

BACKX, S. O serviço social na educação. In: REZENDE, I.; CAVALCANTI, L. F. Serviço Social e políticas sociais. 2. ed. Rio de Janeiro: UFRJ, p.121-37, 2008.

BEHRING, E.R; BOSCHETTI, I. Política social: fundamentos e história. São Paulo: Cortez, 2008. (Biblioteca Básica de Serviço Social, 2)

DAL BELLO, M. Descumprimento de condicionalidade na educação: subsídios à política de assistência social. O Social em Questão, Rio de Janeiro, Ano 19, v. 2, n. 36, p. 239-264, nov./dez. 2016.

FREIRE, P. Pedagogia da Autonomia: saberes necessários à prática educativa. São Paulo: Paz e Terra, 2002.

, P. Pedagogia do Oprimido. São Paulo: Paz e Terra, 2007.

NERI, M. O Programa Cartão Família Carioca: Diagnóstico e Desenho. Rio de Janeiro. Centro de Políticas Sociais (CPS/FGV), 2010.

SILVA, M. O. da S e L; ALMADA,V. F. dos S (coord.). Avaliando o Bolsa Família: unificação, focalização e impactos. São Paulo: Cortez, 2010.

YAZBEK, M. C. Classes Subalternas e Assistência Social. São Paulo: Cortez, 2003.

\section{Sites consultados:}

História do bairro de Magalhães Bastos. Disponível em: <www.magalhaesbastos.com.br/historia-do-bairro/> Acessado em 03/01/2017 
Pesquisa de CRE`s. WEB site Secretaria Municipal de Educação do Rio de Janeiro.

<www.webapp.sme.rio.ri.gov.br/jcartela/publico/pesquisa.do?cmd=listCres>

Acessado em 03/01/2017

Bairros Cariocas em Armazém de Dados. Disponível em:

$<$ www.portalgeo.rio.ri.gov.br/bairroscariocas/index bairro.htm $>$ Acessado em 03/01/2017

Notícia Ministério da Educação (2005): "MEC lança Projeto Presença". Disponível em:

$<$ www.portal.mec.gov.br/busca-geral/211-noticias/218175739/3900-mec-lanca-

projeto-presenca> Acessado em 08/01/2017

Ministério da Educação: “Acompanhamento da frequência escolar de crianças e jovens em vulnerabilidade condicionalidade em educação do Programa Bolsa Família". Disponível em:

$<$ www.portal.mec.gov.br/pnaes/194-secretarias-112877938/secad-educacaocontinuada-223369541/17451-acompanhamento-da-frequencia-escolar-decriancas-e-jovens-em-vulnerabilidade-condicionalidade-em-educacao-doprograma-bolsa-familia-pbf-novo> Acessado em 08/01/20

Sanções sobre os descumprimentos do Programa Bolsa Família. Disponível em: $<$ www.bolsafamiliacol.webnode.com.br/bolsa-

familia/condicionalidades/san\%C3\%A7\%C3\%B5es/> Acessado em 08/01/2017

Sobre as Metas do Milênio. Disponível em:<http://www.institutoatkwhh.org.br/compendio/?q=node/19> Acessado em $10 / 01 / 2017$

Site Projeto Aluno Presente. Disponível em:

<http://www.alunopresente.org.br/> Acessado em 13/01/2017.

Site Observatório de Favelas. Disponível em:

http://observatoriodefavelas.org.br/ Acessado em 13/01/2017. 